\title{
A Developmental Study of Heavy Episodic Drinking Among College Students: The Role of Psychosocial and Behavioral Protective and Risk Factors*
}

\author{
RICHARD JESSOR, PH.D., ${ }^{\dagger}$ FRANCES M. COSTA, PH.D., PATRICK M. KRUEGER, PH.D., ${ }^{\dagger}$ AND MARK S. TURBIN, M.A. \\ Institute of Behavioral Science, 483 UCB, University of Colorado, Boulder, Colorado 80309-0483
}

\begin{abstract}
Objective: A theory-based protection/risk model was applied to explain variation in college students' heavy episodic drinking. Key aims were (1) to establish that psychosocial and behavioral protective factors and risk factors can account for cross-sectional and developmental variation in heavy episodic drinking, and (2) to examine whether protection moderates the impact of risk on heavy episodic drinking. Method: Random- and fixed-effects maximum likelihood regression analyses were used to examine data from a three-wave longitudinal study. Data were collected in fall of 2002, spring of 2003, and spring of 2004 from college students $(N=975 ; 548 \mathrm{men})$ who were firstsemester freshmen at Wave 1. Results: Psychosocial and behavioral protective and risk factors accounted for substantial variation in collegestudent heavy episodic drinking, and protection moderated the impact of risk. Findings held for both genders and were consistent across the
\end{abstract}

\begin{abstract}
three separate waves of data. Key predictors of heavy episodic drinking were social and individual controls protection (e.g., parental sanctions for transgression and attitudinal intolerance of deviance, respectively); models risk (peer models for substance use); behavioral protection (attendance at religious services); and behavioral risk (cigarette smoking and marijuana use). Changes in controls protection, models risk, and opportunity risk were associated with change in heavy episodic drinking. Conclusions: An explanatory model based on both psychosocial and behavioral protective and risk factors was effective in accounting for variation in college-student heavy episodic drinking. A useful heuristic was demonstrated through the articulation of models, controls, support, opportunity, and vulnerability to characterize the social context, and of controls, vulnerability, and other behaviors to characterize individuals. (J. Stud. Alcohol 67: 86-94, 2006)
\end{abstract}

$\mathrm{P}$ ROBLEM USE OF ALCOHOL among college students is a serious public health problem in the United States (Goldman, 2002; Keeling, 1998; Wechsler et al., 2000, 2002). Nearly half of college students surveyed reported "getting drunk" as a reason for drinking, and 39\%-44\% have reported heavy episodic drinking (so-called "binge drinking") (Johnston et al., 2004; Wechsler et al., 2002). Excessive alcohol use adversely affects not only student drinkers, but their peers as well (Abbey, 2002; Hingson et al., 2002, 2005; Meilman, 1993; Perkins, 2002; Wechsler et al., 1998a, 2002).

This study tests an explanatory model of both proximal and distal psychosocial and behavioral protective factors and risk factors as an account of heavy episodic drinking in a college student sample. It also investigates whether developmental change in these protective and risk factors is related to change in heavy episodic drinking over the first

Received: June 15, 2005. Revision: September 28, 2005.

*This study was supported by Colorado Tobacco Research Program grant 2R-041. Additional support was provided by the Office of the Vice Chancellor of Student Affairs, University of Colorado, Boulder.

tCorrespondence may be sent to Richard Jessor at the above address, or via email at: jessor@colorado.edu. Patrick M. Krueger is with the Robert Wood Johnson Health and Society Scholars Program, Department of General Internal Medicine, University of Pennsylvania, Philadelphia, PA.
2 years of college. In recent years, there has been a growing interest in the role of protective factors and risk factors in influencing adolescents' involvement in problem behaviors (e.g., problem drinking and the use of illicit drugs) (Jessor, 1991, 1998). This protection/risk model, derived from Problem-Behavior Theory (Jessor et al., 1991; Jessor and Jessor, 1977), has been used to explain problem drinking, including heavy episodic drinking, in samples of middle school and high school students (Costa et al., 1999; Jessor et al., 2003).

Protective factors decrease the likelihood of engaging in such problem behaviors as heavy episodic drinking. Psychosocial protective factors provide social models for positive or prosocial behavior (e.g., peer models for conventional behaviors such as volunteer work, parent models for healthenhancing behaviors such as regular exercise); social and personal controls against norm-violative behavior (e.g., parental sanctions for transgression, attitudinal intolerance of deviance); and an environment of social support (e.g., family closeness). Behavioral protective factors refer to actual involvement in positive or prosocial activities (e.g., volunteer work or attendance at religious services) that promote conventional attitudes and values and embed young people in more conventional social groups. Protective factors are posited not only to decrease the likelihood of problem behavior involvement, but also to moderate (decrease) the impact of exposure to risk factors. 
Risk factors, on the other hand, increase the likelihood of engaging in problem behaviors. Psychosocial risk factors influence involvement in such problem behaviors as heavy episodic drinking by providing models for problem behavior (e.g., peer models for heavy episodic drinking); providing opportunity for engaging in problem behavior (e.g., ready availability of alcohol); and constituting social or personal vulnerability to engaging in problem behavior (e.g., peer pressure for drinking, low self-esteem). Behavioral risk factors refer to involvement in other problem behaviors (e.g., cigarette smoking and use of illicit drugs) that constitute opportunities and encouragement for also engaging in the problem behavior of heavy episodic drinking.

A great deal of descriptive information is available on U.S. college students' alcohol use and misuse (quantity and frequency of use, prevalence of heavy episodic drinking, and negative consequences of use) and on comparative levels of use across gender, race/ethnicity, and other demographic characteristics (Johnston et al., 2004; Meilman et al., 1997; O'Malley and Johnston, 2002; Wechsler et al., 2000,2002 ). Current reviews of research on college drinking, however, stress the need for multivariate studies, for tests of theoretical models, for assessment of mediation and moderation effects, and for longitudinal designs (Baer, 2002; Ham and Hope, 2003).

Among recent studies that have had an explanatory focus, most have concentrated on proximal factors, including perception of norms about drinking (Perkins, 2003; Perkins and Wechsler, 1996), motives for drinking (Galen and Rogers, 2004; Read et al., 2003), and especially, alcohol expectancies (e.g., Aarons et al., 2003; Del Boca et al., 2004; Gotham et al., 1997; Greenbaum et al., 2005; Sher et al., 1996; Wood et al., 2001). A comprehensive understanding of developmental change in college drinking has not yet emerged from the literature. Although students may bring high school drinking patterns to college (Wechsler et al., 1994; Weitzman et al., 2003; Yu and Shacket, 2001), continuation or variation in those patterns is likely to be affected by later experiences, including those in the college context itself. Living in a dormitory or apartment, for example, entails diminished exposure to parental controls and more frequent exposure to peer influences, as well as to opportunities to engage in such problem behaviors as drinking and the use of other drugs (Bachman et al., 1996; D'Amico et al., 2005; Maggs, 1997; Read et al., 2005; Schulenberg and Maggs, 2002). In addition, the new and unfamiliar college environment may include expectations and challenges that, at least for some students, can result in increased stress, lowered self-esteem, and depression, all of which constitute vulnerability to involvement in problem behaviors (e.g., heavy alcohol use) (Aseltine and Gore, 1993; Gore et al., 1997).

The protection/risk model applied in the present longitudinal research comprises a systematic set of protective and risk factors, derived from the instigations and controls constructs in Problem-Behavior Theory (see Jessor, 1991; Jessor et al., 1995), that take into account key aspects of the college context and of the individual student. The test of the model engages three research objectives: (1) to establish that psychosocial and behavioral protective factors and risk factors can account for variation in college students' heavy episodic drinking, (2) to examine whether protection moderates the impact of exposure to risk on college students' heavy episodic drinking, and (3) to explore whether changes in protective and risk factors can account for changes in heavy episodic drinking during the early college years.

\section{Method}

\section{Study design, participants, and procedures}

Data for this study are from a 2-year, three-wave longitudinal study of alcohol use among college freshmen at the University of Colorado (CU), Boulder. A self-administered 32-page Survey of Personal and Social Development at CU (SPSD) questionnaire included well-established measures of a broad range of theoretically derived psychosocial and behavioral protective and risk factors (Jessor, 1991; Jessor et al., 1995, 2003), as well as of alcohol use. Privacy of responses was safeguarded by a Confidentiality Certificate, which was obtained from the National Institutes of Health.

In the fall of 2002, first-semester freshman students who were at least 18 years old and had just graduated from high school $(N=975 ; 548$ men) participated in Wave 1 of the survey. The Wave 1 participants were closely representative of the entire freshman class. There were no significant differences between students in the Wave 1 sample and the other students in the freshman class $(N=4,094)$ on high school grades, admission test scores, or their grades at the end of the first year of college. The gender and racial/ ethnic composition of the Wave 1 sample was not only similar to the composition of the entire freshmen class, but also to the composition of undergraduate students attending colleges and universities across the U.S. (see Wechsler et al., 1998b). A majority (56\%) of the Wave 1 participants were male and $54 \%$ were in-state (Colorado) residents. Most (87\%) of the sample self-described as white; $5 \%$ as Hispanic/Latino, $1 \%$ as African American, $5 \%$ as Asian American, and $2 \%$ as American Indian. Sixteen percent of participants ( $23 \%$ of the women, $11 \%$ of the men) were affiliated with a fraternity or sorority.

To achieve an adequate-sized sample representative of the freshman class, participants were recruited by two means: (1) mail and email sent to a stratified random sample of freshmen drawn from university records, and (2) flyers inviting freshmen to participate, posted in each building in which the survey was administered. The students received 
payment for filling out the questionnaires, and all participants signed informed consent forms.

Students recruited by mail $(n=282)$ and by flyers $(n=$ 693) were compared on their Wave 1 demographic characteristics and on Wave 1 psychosocial and behavioral measures from the SPSD. Of the students recruited by mail, a majority (54\%) were women; of those recruited by a flyer, a majority $(60 \%)$ were men. In-state students were $63 \%$ of the mail subsample and $51 \%$ of the flyer subsample. There were about equal proportions of each subsample that were nonwhite and equal proportions that were affiliated with a fraternity or sorority. Participants recruited by mail were generally more conventional and less prone to problem behavior, compared with students recruited by flyer and with the population of freshman students as a whole. Despite these observed subsample mean differences, relations between the predictors and criterion were not biased by subsample differences. In separate regression analyses a subsample dummy variable was included, along with its interaction with each protective and risk factor. There were no significant interactions with the dummy variable (i.e., the effects of the predictor measures did not differ between the two subsamples). Combining the two subsamples provided the final Wave 1 sample $(N=975)$ that, as noted earlier, was representative of the CU freshman class as a whole and provided the increased variability sought on the key measures in the research.

Wave 2 data and Wave 3 data were collected from students still enrolled at the university in the spring of 2003 and in the spring of 2004, respectively. At Wave 2, 785 of the Wave 1 participants were resurveyed (this number represented $81 \%$ of Wave 1 participants, and $86 \%$ of those participants still enrolled at CU). At Wave 3, 709 Wave 1 participants $(73 \% ; 85 \%$ of those still enrolled at $\mathrm{CU})$ were resurveyed. The effect of attrition bias on the final regression models was tested with a two-stage selection model (Berk, 1983; Heckman, 1979). Inverse mills ratios, a transformation of the predicted probabilities of dropout and other nonparticipation in the subsequent waves (Dubin and McFadden, 1984), were included in supplementary regression analyses; there was no evidence that nonrandom attrition from the sample biased the relations between protective and risk factors and the heavy episodic drinking criterion measure.

In order to focus on variation among drinkers, the sample for analysis was restricted to those students who had ever drunk alcohol by at least one of the three waves of the survey. Abstainers (those who reported never having drunk alcohol; $n=84$ ) were excluded from analyses.

\section{Measurement of heavy episodic drinking}

Heavy episodic drinking was assessed with the question, "In the past month, how many times did you drink five or more drinks when you were drinking?" Responses ranged from "never" to "more than twice a week," on a 7 point scale. This criterion measure correlated with measures of two other indicators of problem drinking as follows: Correlation was .84 with an item that assessed frequency of drunkenness in the past month and .40 with a sevenitem scale that assessed negative consequences of drinking in the past month (e.g., getting into trouble with one's parents, and having problems at school or with schoolwork). These data provide support for the validity of the heavy episodic drinking criterion measure.

Prevalence of drinking and heavy episodic drinking. At Wave 1, when study participants were first-semester freshmen, more than three fourths of the students $(76 \%$ of men and $80 \%$ of women) reported that they had drunk alcohol in the past month, and $53 \%$ (58\% of men and $47 \%$ of women) reported heavy episodic drinking at least twice in the past month. Recent national surveys indicate that two thirds of students had drunk alcohol in the past month and that $39 \%-44 \%$ reported heavy episodic drinking in the past 2 weeks (Johnston et al., 2004; Wechsler et al., 2000). The descriptive findings from the present sample are generally consistent with those from national-sample surveys with respect to alcohol use; however, prevalence of drinking in the past month and of heavy episodic drinking was somewhat higher in the present sample.

Comparisons across sociodemographic groups on heavy episodic drinking. Consistent with prior research (Baer, 2002; Ham and Hope, 2003), heavy episodic drinking mean scores were significantly higher $(p<.01)$ for men than for women, for white students than for nonwhite students, and for fraternity/sorority members than for nonmembers. In addition, out-of-state students reported more frequent heavy episodic drinking than did in-state students $(p<.001)$. In the multivariate regression analyses reported below, sociodemographic differences were partialled out.

\section{Measurement of psychosocial and behavioral protective factors and risk factors}

Three types of psychosocial protection (models, controls, support) and three types of psychosocial risk (models, opportunity, vulnerability) were measured. Each multiple-item measure was constructed by standardizing the items to give them equal weight and taking their mean.

Measurement of psychosocial protective factors. Models protection/family is a six-item scale $(\alpha=.75)$ that assesses parental models for health-enhancing behavior (e.g., "Do your parents [or the adults who raised you] pay attention to eating a healthy diet themselves?"). Having such models encourages participation in health-enhancing behaviors and avoidance of health-compromising behaviors (e.g., excessive alcohol use). Models protection/peers is a five-item scale $(\alpha=.63)$ that assesses friends as models for conventional behavior (e.g., "How many of your friends do 
volunteer work in the community?"). Having such models reflects greater involvement with conventional peers and more exposure to conventional activities.

Controls protection/social comprises 10 items $(\alpha=.78)$ derived from three multiple-item scales that assess social regulation: (1) parental disapproval of problem behavior (e.g., "When you were in middle school and high school, how did your parents feel about kids who drank alcohol?"); (2) friends' disapproval of problem behavior (e.g., "How do most of your friends or acquaintances at $\mathrm{CU}$ feel about someone your age using marijuana?"); and (3) friends' controls against transgression (e.g., "If your friends or acquaintances at CU thought you were violating CU's policy about academic dishonesty, would they try to stop you?"). Perceived social disapproval should serve as a social control that inhibits norm-violative behavior, including heavy episodic drinking. Controls protection/individual is composed of 15 items $(\alpha=.78)$ derived from four multiple-item scales that assess attitudinal intolerance of deviance (e.g., "How wrong do you think it is to cheat on tests or homework?"); religiosity (e.g., "How important is it to you to rely on religious teachings when you have a problem?"); positive attitude toward college (e.g., "I'm satisfied with the education I'm receiving at $C U$ "); and perceived health effects of health-compromising behavior (e.g., "Do you' think regular use of alcohol can have an effect on the health of people your age?"). These various aspects of personal regulation should deter engaging in behaviors (e.g., excessive alcohol use) that may be detrimental to health as well as violative of conventional social norms.

Support protection was measured using five items ( $\alpha=$ .72) that assess family closeness (e.g., "It's fun when my family does things together") and express interest and support from teachers (e.g., "My teachers at CU try to help students when they are having problems"). Positive relationships with adults, both at home and in college, provide a supportive environment for conventional behavior; behavior that violates social norms may risk the loss of that support.

Measurement of psychosocial risk factors. Models risk/ peers is an eight-item scale $(\alpha=.77)$ that assesses social models for substance use among friends and among other students at the university (e.g., "How many of your friends or acquaintances at CU use marijuana?"). Exposure to peer models for substance use can influence students to engage in these behaviors.

Opportunity risk was assessed by an item that asks, "If you wanted some beer, wine, or liquor, how easy would it be for you to get some?" Social contexts that offer easy availability of alcohol should enhance the likelihood of engaging in heavy episodic drinking.

Vulnerability risk/peers is measured using a three-item scale $(\alpha=.67)$ that assesses perceived peer pressure to smoke and drink' (e.g., "Do your friends or acquaintances at CU ever encourage you to get drunk?"). Social pressure to smoke and drink constitutes a self-evident risk factor for substance use, including heavy episodic drinking. Vulnerability risk/individual is composed of eight items $(\alpha=.68)$ derived from two multi-item component scales, both of which measure personal vulnerability to problem behavior: felt stress (e.g., "In the past month, how much stress or pressure have you felt because of your schoolwork?") and low self-esteem (e.g., "How well do you make decisions about important things in your life?"). High levels of stress and low self-esteem both constitute psychosocial risk because substance use, including heavy episodic drinking, may be perceived and used as a way to cope with negative feelings.

Measurement of the behavioral protective factor. Behavioral protection was assessed using an item asking about frequency of attendance at church or religious services during the past month. Attendance at religious services constitutes behavioral protection because it tends to promote orientations and social networks incompatible with behaviors that violate social norms.

Measurement of behavioral risk factors.' Behavioral risk was assessed with measures of three other problem behaviors-cigarette smoking, marijuana use, and delinquent-type behavior. Cigarette smoking was assessed with the item: "During the past month, how many cigarettes have you smoked on an average day?" Response options ranged from 1 ("none at all") to 9 ("about 2 packs or more a day"). Marijuana use was measured with the item: "In the past month, how often have you used marijuana (or hash)?" Response options ranged from 1 ("not at all") to 7 ("every day"). On the latter two measures, never-users were assigned a score of zero. Delinquent-type behavior is a sevenitem scale $(\alpha=.71)$ that assesses frequency in the past month of engaging in the behaviors stealing, cheating, vandalism, and aggression. Smoking and marijuana use constitute risk because they also involve substance use. Participation in delinquent-type behavior suggests a general tolerance for norm-violating behaviors that may also include heavy episodic drinking.

All bivariate correlations of the protective and risk factors with the heavy episodic drinking criterion measure were significant and in the theoretically expected directions, except two that were essentially zero (models protection/family and vulnerability risk/individual). The predictors with the largest correlations were controls protection/social (-.38), models risk/peers (.38), cigarette smoking (.33), and marijuana use (.42); the other correlations were in the $.10 \mathrm{~s}$ and $.20 \mathrm{~s}$.

\section{Results}

\section{Accounting for college student heavy episodic drinking: A test of the explanatory model}

In order to summarize, in a single analysis, the key patterns in the data across the three separate waves, the heavy 
episodic drinking criterion measure was regressed on the set of protective and risk factors in a random-effects maximum likelihood linear regression analysis (Johnson, 1995). The data were transformed into a pooled time-series data set. Each participant contributed one record for each wave for which he or she reported having ever drunk alcohol and had complete data for this analysis $(n=858)$. The data wave in which each observation was recorded is indicated by a variable for the number of months that students had been in college at that wave. Because the factors that affect heavy episodic drinking may be correlated over time, within students, independence among the observations cannot be assumed. The random-effects model accounts for this nonindependence and accurately estimates the standard errors (Rabe-Hesketh and Everitt, 2004) by fitting a linear regression that allows individuals to deviate from the mean intercept, while observations can deviate from individualspecific intercepts. (Additional analyses, using random-effects ordered logistic regression for the pooled time-series data, found results that were similar in direction, magnitude, and level of significance; not tabled, tables available from the authors.)

Results from the random-effects linear regression analysis are shown in Table 1. Frequency of heavy episodic drinking was significantly $(p<.05)$ associated with two of the five psychosocial protective factors (controls protection/social and controls protection/individual); with three of the four psychosocial risk factors (models risk/peers, opportunity risk, and vulnerability risk/peers); with the behavioral protective factor (church attendance); and with two of the three behavioral risk factors (cigarette smoking and marijuana use). Thus, at least one measure in each of the four sets of theoretical predictors was significant in the randomeffects regression model, indicating that each type of protection and risk is relevant in the account of heavy episodic drinking (i.e., some unique variance was accounted for by each set of predictors).

To test for moderator effects, interactions between psychosocial protective and risk factors and between behavioral protective and risk factors were tested for significance, and the model was then re-estimated, omitting the nonsignificant interactions. Models Protection/Family moderated the effect of Vulnerability Risk/Peers, in that the positive relationship between Vulnerability Risk/Peers (peer pressure) and heavy episodic drinking is attenuated for students with above-average levels of Models Protection/Family. In addition, Support Protection moderated the effect of Vulnerability Risk/Individual. Vulnerability Risk/Individual (stress, low self-esteem) is not a significant risk factor for most students, except for those students with low levels of Support Protection.

The proportion of criterion variance accounted for by the set of protective and risk factor measures is not available from the random-effects maximum likelihood regres-
TABLE 1. Random-effects maximum likelihood linear regression and fixedeffects maximum likelihood linear regression of heavy episodic drinking on psychosocial and behavioral protective and risk factors: Final model, Waves $1-3^{a}$

\begin{tabular}{|c|c|c|}
\hline Measures entered & $\begin{array}{l}\text { Random-effects } \\
\text { model } b_{\bullet}^{b} \\
\text { final step }\end{array}$ & $\begin{array}{l}\text { Fixed-effects } \\
\text { model } b{ }^{b} \\
\text { final step }\end{array}$ \\
\hline \multicolumn{3}{|l|}{ Sociodemographic background } \\
\hline Months in college & $.02 \ddagger$ & $.02 \ddagger$ \\
\hline Gender $($ male $=-1$, female $=1)$ & $-.25 t$ & 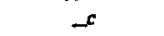 \\
\hline In-state student & $-.15^{\dagger}$ & - \\
\hline Fraternity/sorority & $.50 \%$ & - \\
\hline Nonwhite & $-.40^{\dagger}$ & - \\
\hline Socioeconomic status & .00 & - \\
\hline \multicolumn{3}{|l|}{ Psychosocial protective factors } \\
\hline Models protection/family & .07 & .08 \\
\hline Models protection/peers & .01 & .00 \\
\hline Controls protection/social & $-.47 \ddagger$ & $-.50 t$ \\
\hline Controls protection/individual & $-.22 *$ & $-.32^{*}$ \\
\hline Support protection & .04 & .13 \\
\hline \multicolumn{3}{|l|}{ Psychosocial risk factors } \\
\hline Models risk/peers & $.47 \ddagger$ & .291 \\
\hline Opportunity risk & $.12^{\ddagger}$ & $.11^{*}$ \\
\hline Vulnerability risk/peers & $.10^{*}$ & .09 \\
\hline Vulnerability risk/individual & -.13 & -.03 \\
\hline \multicolumn{3}{|c|}{ Psychosocial Protection $\times$ Risk interactions } \\
\hline \multicolumn{3}{|c|}{ Models Protection/Family $x$} \\
\hline Vulnerability Risk/Peers & $-.13^{*}$ & $-.15^{*}$ \\
\hline \multicolumn{3}{|l|}{ Support Protection $\times$} \\
\hline Vulnerability Risk/Individual & $-.28^{\dagger}$ & - \\
\hline \multicolumn{3}{|l|}{ Models Protection/Peers $x$} \\
\hline Models Risk/Peers & - & $-.18^{\S}$ \\
\hline \multicolumn{3}{|l|}{ Behavioral protective factor } \\
\hline Church attendance & $-.12^{\dagger}$ & $-.08^{\S}$ \\
\hline \multicolumn{3}{|l|}{ Behavioral risk factors ' } \\
\hline Cigarette smoking & $.25 \ddagger$ & .05 \\
\hline Marijuana use & $.34 t$ & .12 \\
\hline Delinquent behavior & .04 & .01 \\
\hline
\end{tabular}

Notes: $N=858$, each with complete data from at least one of the three waves of the survey; no. of observations $=2,053$. These analyses include only those who were ever-drinkers in at least one wave; bunstandardized regression coefficients; standardized coefficients are inappropriate with interaction terms (see Aiken and West, 1991, pp. 40-47); ${ }^{c}$ the relationship between heavy episodic drinking and time-invariant variables-gender, residency, participation in Greek life, race, and socioeconomic statuscannot be estimated in fixed-effects models.

$\S_{p}<.10 ;{ }^{*} p<.05 ;{ }^{\dagger} p<.01 ;{ }^{\ddagger} p<.001$; one-tailed $t$ tests.

sion analysis but can be determined from ordinary least squares (OLS) regression analysis of the data from each wave. Those analyses (not tabled; tables available from the authors) showed that, after controlling for sociodemographic background variables, the protective and risk factors accounted for an additional quarter of the variance in heavy episodic drinking in each of the three data waves $(22 \%$, $23 \%$, and $27 \%$ ). OLS regression analyses also provide the proportion of variance accounted for uniquely by each set of theoretical predictors-psychosocial and behavioral protection and risk factors-by assessing the decrease in $R^{2}$ when each set is deleted, in turn, from the complete model (Cohen and Cohen, 1983). The largest proportion of unique variance was accounted for by the behavioral risk factors, ranging from $4 \%$ to $6 \%$ across the three waves. Psychosocial 
risk accounted uniquely for $2 \%-6 \%$ of variance; psychosocial protection accounted uniquely for $1 \%-2 \%$; and behavioral protection accounted uniquely for less than $1 \%$ in each wave.

Overall, these findings provide support for the protection/risk explanatory model in relation to the first two research objectives: The protection/risk model provides a substantial account of variation in college-student heavy episodic drinking; each type of protective and risk factors is important in that account; and there is evidence for protection moderating the effects of exposure to risk.

\section{Accounting for developmental change in college-student heavy episodic drinking}

To determine whether the same explanatory model can account for developmental change in heavy episodic drinking, a fixed-effects maximum likelihood linear regression model was used to examine the relationship between changes in the protective and risk factors and changes in heavy episodic drinking across the three waves of data and the 14-month interval. Fixed-effects regression estimates the effect of intra-individual changes in the independent variables on intra-individual changes in the dependent variable (Allison, 1994; Johnson, 1995), while removing any bias in coefficients that results from observed or unobserved factors that do not change over time. Thus, effects of the time-invariant sociodemographic measures cannot be estimated and are not included in this analysis. Fixed-effects models control for time-invariant but unobserved differences that may emerge when using samples that are less than perfect random samples (StataCorp, 2003).

The results of the fixed-effects regression of change in heavy episodic drinking on changes in the predictors are also shown in Table 1. The positive coefficient for the months-in-college measure indicates that the average student increased his or her frequency of heavy episodic drinking across the three waves. Among the psychosocial protective factors, changes in controls protection/social and controls protection/individual were, as expected, negatively associated with changes in heavy episodic drinking. These are the same predictor measures that were significant in the random-effects model. Among the psychosocial risk factors, changes in models risk/peers and opportunity risk were positively associated, as expected, with changes in heavy episodic drinking. None of the behavioral protective and risk factors was significant, indicating that change in heavy episodic drinking was not related to within-person variability in these other behaviors over time, after controlling for changes in psychosocial protection and risk.

Change in Models Protection/Family moderated the relationship between change in Vulnerability Risk/Peers and change in heavy episodic drinking, in that change in Vulnerability Risk/Peers was more strongly associated with change in heavy episodic drinking for those students who decreased in Models Protection/Family. Models Protection/ Family was also one of the significant moderators in the random-effects analysis. An additional moderator effect was just over the .05 significance level $(p=.054)$; change in Models Risk/Peers was more strongly associated with change in heavy episodic drinking for those students who decreased in Models Protection/Peers.

To examine further the relationship between within-individual changes in heavy episodic drinking and withinindividual changes in protection or risk at the person level, mean changes in protection and risk were examined within two subgroups: (1) students whose heavy episodic drinking increased from Wave 1 to Wave 3 ( $45 \%$ of the Wave 1 ever-drinkers) and (2) students whose heavy episodic drinking stayed the same or decreased. Analyses of variance (not tabled; tables available from the authors) showed that, although there was an increase in controls protection/social for both subgroups, the increase was significantly smaller for those students whose heavy episodic drinking increased. Church attendance declined more for those whose heavy episodic drinking increased than for those whose heavy episodic drinking stayed the same or decreased. With regard to the risk factors, there were increases over time in most of the risk factors in both subgroups (peer models for substance use, availability of alcohol, peer pressure for substance use and marijuana use); however, the increases were significantly larger for those students whose heavy episodic drinking increased.

In summary, developmental change in heavy episodic drinking over the first 2 years of college was primarily associated with change in aspects of the social environment (controls protection/social, models risk/peers, and opportunity risk), as well as with change in controls protection/ individual; the effect of change in vulnerability risk/peers was attenuated for those who increased in models protection/family. Interactions of gender with the protective and risk factors in all regression models were tested for significance, and, with only one exception (in the Wave 2 OLS regression), parameter estimates did not differ for men and women.

\section{Discussion}

The findings provide support for the psychosocial and behavioral protection/risk explanatory model, accounting for significant variation in heavy episodic drinking in this sample of college students. Both protective factors and risk factors contributed uniquely to the variance accounted for. The lower the protection and/or the higher the risk, the more frequent the engagement in heavy episodic drinking. There is also empirical support for the role of psychosocial protection as a moderator of the impact of psychosocial risk on heavy episodic drinking. Findings were similar 
across three separate data waves and across alternative analytic methods, and they apply similarly to college men and college women. The explanatory model also accounted significantly for change in heavy episodic drinking across the first 2 years of college.

It is important to note that it was the social contexts in which college students are embedded-both family and peer contexts-that emerged as salient in these analyses. Although their salience could, of course, depend on the adequacy of the individual-level measures, it is the case that measures of controls protection/individual, especially intolerance of deviance, have historically been strong and consistent predictors of problem drinking and other problem behaviors in samples of secondary school students, college students, and young adults (Jessor and Jessor, 1977; Jessor et al., 1991). Coefficients for controls protection/individual in both the random-effects and fixed-effects models, although significant, are considerably weaker than those for controls protection/social. Controls protection/social (a composite measure that included both peer controls and parental and peer disapproval) and models risk/peers generally had the largest main effects on heavy episodic drinking. Controls protection/social had also emerged in earlier research as a key protective factor in relation to alcohol use and other problem behavior involvement among students in middle school and high school (Costa et al., 2005). The importance of peer models as a social-context risk factor is also consistent both with earlier applications of the protection/risk model to samples of secondary-school students (Costa et al., 1999, 2005; Jessor et al., 2003) and with current literature on college drinking (Borsari and Carey, 2001; Ham and Hope, 2003; Schulenberg and Maggs, 2002).

Consistent evidence was found for two moderator effects. Although vulnerability risk/individual was not a significant risk factor for the sample as a whole, the moderator effect of support protection indicates that vulnerability risk/ individual (high stress and low self-esteem) is, indeed, associated with more frequent heavy episodic drinking for those students with low perceived support from parents and teachers. The moderator-effect of models protection/family indicates that when models protection/family (parental models forihealth=enhancing behavior) was high, the impact of vulnerability risk/peers (peer pressure for drinking and smoking) on hieavy episodic drinking was attenuated. These moderator findings suggest that positive adult influences (support and ${ }^{1}$ models) can diminish the impact of risk factors on heavy episodic drinking among college students.

Establishing signifioant moderator effects is important for the theory beliind the protection/risk explanatory model. It is well established that moderator effects are difficult to detect in nonexperimental field.studies and that effects are typically small, involving only from $1 \%$ to $3 \%$ of the variance (Chaplin, 1991; McClelland and Judd, 1993). In the present study, the moderator effêcts, (accounting for about
$1 \%$ of variance) are noteworthy for their consistency across both random- and fixed-effects regression analyses.

Consonant with findings from other research in samples of college students (Fenzel, 2005; Kim et al., 1997; Wechsler et al., 1995), more frequent church attendance was associated with less frequent heavy episodic drinking; other problem behaviors (e.g., cigarette smoking and marijuana use) were associated with more frequent heavy episodic drinking. These findings are also consonant with the covariation that has been well-established among various problem behaviors (Donovan and Jessor, 1985; Donovan et al., 1988; Elliott, 1992; Jessor and Jessor, 1977; Osgood et al., 1988).

Heavy episodic drinking, the focus of this study, is only one facet of a pattern of problem drinking in college. Frequency of drunkenness was also examined as a criterion measure in additional regression analyses, and results were very similar to those for the heavy episodic drinking measure; proportions of variance accounted for were similar and the key predictors from the explanatory model were essentially the same ones.

As in many other studies (Fenzel, 2005; Ham and Hope, 2003), college men in the present study reported higher frequencies of heavy episodic drinking than did college women. Despite this expected difference in mean levels, the same psychosocial and behavioral protective and risk factors, with only one exception, were related to heavy episodic drinking for both men and women in both the crosssectional and the longitudinal analyses. The absence of gender differences in the ways in which protective and risk factors influence heavy drinking among college students is an important finding, and it is also consistent with recent findings of others (Fenzel, 2005).

The salience of contextual protective factors in the present findings suggests the importance of intervention efforts targeted at the context of college life itself. Controls and supports were the most salient aspects of context, emphasizing the role of rules, regulations, and clear standards in a supportive environment. The significance of adult figures (parents and teachers) in the lives of college students was reinforced by the findings that parent and teacher support moderated the impact of personal vulnerability risk (stress and low self-esteem) on students' heavy episodic drinking and that parent models for health behavior moderated the impact of peer pressure for substance use. Last, the relationships of the behavioral risk measures (cigarette smoking and marijuana use) with heavy episodic drinking suggest that intervention efforts might well target the larger pattern of substance use behavior, rather than programming for each of the behaviors separately.

There are several limitations to the study that should be emphasized. First, the sample was drawn from a single university and this, of course, constrains the generalizability of the findings. Nevertheless, since the primary aim of the 
study was to test the adequacy of an explanatory model, a single university sample is entirely appropriate for that objective. Replication of the model in tests on other campuses seems a promising undertaking. The findings are also consistent with findings when the model was applied to students in secondary school (Costa et al., 1999; Jessor et al., 2003). A second limitation is that participants did not constitute a random sample. They did constitute about one fifth of the entire freshman class, however, and they were shown to be closely representative of that class on indicators of academic achievement, race/ethnicity, and gender.

A third limitation is that measurement of several variables relied on a single item. A single-item measure of heavy episodic drinking is widely used, however (Ham and Hope, 2003), and in the present study it was shown to correlate substantially with other measures of problem drinking (i.e., frequency of drunkenness and negative consequences of drinking). In addition, the four single-item measures of the protection and risk predictors all emerged as consistent and significant predictors of the heavy episodic drinking criterion measure, consonant with our earlier research.

The results were consistent, overall, in three separate data waves, across different analytic methods, in both crosssectional and longitudinal analyses, and for both genders. The study has shown that the protective and risk factors articulated in the explanatory model play a significant role in college-student heavy episodic drinking across the early college years.

\section{Acknowledgment}

The authors are grateful to Dr. Ronald J. Stump and Robert N. Maust for their support.

\section{References}

aarons, G.A., Goldman, M.S., Greendaum, P.E., and Coovert, M.D. Alcohol expectancies: Integrating cognitive science and psychometric approaches. Addict. Behav. 28: 947-961, 2003.

ABBEY, A. Alcohol-related sexual assault: A common problem among college students. J. Stud. Alcohol, Supplement No. 14, pp. 118-128, 2002.

AIKen, L.S. AND WeST, S.G. Multiple Regression: Testing and Interpreting Interactions, Thousand Oaks, CA: Sage, 1991.

AluLson, P.D. Using panel data to estimate the effects of events. Sociol. Meth. Res. 23: 174-199, 1994.

ASELTINE, R.H. AND GORE, S. Mental health and social adaptation following the transition from high school. J. Res. Adolesc. 3: 247-270, 1993.

Bachiman, J.G., Johnston, L.D., O'Malley, P.M., and Schulenderg, J. Transitions in drug use during late adolescence and young adulthood. In: Graber, J.A., Brooks-Gunn, J., And Petersen, A.C. (Eds.) Transitions through Adolescence: Interpersonal Domains and Context, Mahwah, NJ: Lawrence Erlbaum, 1996, pp. 111-140.

BAER, J.S. Student factors: Understanding individual variation in college drinking. J. Stud. Alcohol, Supplement No. 14, pp. 40-53, 2002.

BERK, R.A. An introduction to sample selection bias in sociological data. Amer. Sociol. Rev. 48: 386-398, 1983.

Borsarl, B. AND CAREY, K.B. Peer influences on college drinking: A review of the research. J. Subst. Abuse 13: 391-424, 2001.
CiIAPLIN, W.F. The next generation of moderator research in personality psychology. J. Pers. 59: 143-178, 1991.

Conen, J. ANd Cohen, P. Applied Multiple Regression/Correlation Analysis for the Behavioral Sciences, 2nd Edition, Mahwah, NJ: Lawrence Erlbaum, 1983.

Costa, F.M., JESSOR, R., AND TURBIN, M.S. Transition into adolescent problem drinking: The roles of psychosocial risk and protective factors. J. Stud. Alcohol 60: 480-490, 1999.

Costa, F.M., Jessor, R., Turbin, M.S., Dong, Q., Zhang, H., AND WANG, C. The role of social contexts in adolescence: Context protection and context risk in the United States and China. Appl. Devel. Sci. 9: 67$85,2005$.

D'Amico, E.J., Ellickson, P.L., Wagner, E.F., Turrisi, R., Fromme, K., GHosh-DAsTidar, B., LoNGSHORE, D.L., MCCAFFrEY, D.F., MONTGOMERY, M.J., SCHONLAU, M., AND WruGIT, D. Developmental considerations for substance use interventions from middle school through college. Alcsm Clin. Exp. Res. 29: 474-483, 2005.

Del Boca, F.K., Darkes, J., Greenbaum, P.E., and Goldman, M.S. Up close and personal: Temporal variability in the drinking of individual college students during their first year. J. Cons. Clin. Psychol. 2: 155164, 2004.

Donovin, J.E. AND Jessor, R. Structure of problem behavior in adolescence and young adulthood. J. Cons. Clin. Psychol. 53: 890-904, 1985.

Donovan, J.E., JEsSoR, R., AND COSTA, F.M. Syndrome of problem behavior in adolescence: A replication. J. Cons. Clin. Psychol. 56: 762-765, 1988.

DUBin, J.A. AND McFAdDEN, D.L. An econometric analysis of residential electric appliance holdings and consumption. Econometrica 52: 345362,1984 .

ELtiotT, D.S. Health enhancing and health compromising lifestyles. In: Millistein, S.G., Petersen, A.C., and Nightingale, E.O. (Eds.) Adolescent Health Promotion, New York: Oxford Univ. Press, 1992.

FENZEL, L.M. Multivariate analyses of predictors of heavy episodic drinking and drinking-related problems among college students. J. Coll. Student Devel. 46: 126-140, 2005.

GALEN, L.W. AND RoGers, W.M. Religiosity, alcohol expectancies, drinking motives and their interaction in the prediction of drinking among college students. J. Stud. Alcohol 65: 469-476, 2004.

Goldman, M.S. Introduction. J. Stud. Alcohol, Supplement No. 14, p. 5 , 2002.

Gore, S., Aseltine, R., Jr., Colten, M.E. and Lin, B. Life after high school: Development, stress, and well-being. In: GotuB, I.H. AND WuEAton, B. (Eds.) Stress and Adversity Over the Life Course: Trajectories and Turning Points, New York: Cambridge Univ. Press, 1997, pp. 197-214.

Gothiam, H.J., SHer, K.J., AND Wood, P.K. Predicting stability and change in frequency of intoxication from the college years to beyond: Individual-difference and role transition variables. J. Abnorm. Psychol. 106: 619-629, 1997.

Greendaum, P.E., Del Boca, F.K., Darkes, J., Wang, C.-P., and Goldman, M.S. Variation in the drinking trajectories of freshmen college students. J. Cons. Clin. Psychol. 73: 229-238, 2005.

HAM, L.S. AND HOPE, D.A. College students and problematic drinking: A review of the literature. Clin. Psychol. Rev. 23: 719-759, 2003.

HECKMAN, J.J. Sample selection as a specification error. Econometrica 47: 153-162, 1979.

Hingson, R., HeEren, T., Winter, M., And WeChSLeR, H. Magnitude of alcohol-related mortality and morbidity among U.S. college students ages 18-24: Changes from 1998 to 2001. Annual Rev. Publ. Hith 26: 259-279, 2005.

Hingson, R.W., Heeren, T., Zakocs, R.C., Kopstein, A., and Wechsler, H. Magnitude of alcohol-related mortality and morbidity among U.S. college students ages 18-24. J. Stud. Alcohol 63: 136-144, 2002.

JessoR, R. Risk behavior in adolescence: A psychosocial framework for understanding and action. J. Adolesc. Hlth 12: 597-605, 1991. 
JeSSOR, R. New perspectives on adolescent risk behavior. In: JessOR, R. (Ed.) New Perspectives on Adolescent Risk Behavior, New York: Cambridge Univ. Press, 1998, pp. 1-10.

Jessor, R., Donovan, J.E., and Costa, F.M. Beyond Adolescence: Problem Behavior and Young Adult Development, New York: Cambridge Univ. Press, 1991.

Jessor, R. and Jessor, S.L. Problem Behavior and Psychosocial Development: A Longitudinal Study of Youth, San Diego, CA: Academic Press, 1977.

Jessor, R., Turbin, M.S., Costa, F.M., Dong, Q., Zhang, H., and Wang, C. Adolescent problem behavior in China and the United States: A cross-national study of psychosocial protective factors. J. Res. Adolesc. 13: 329-360, 2003.

Jessor, R., van den Bos, J., VANDerRyn, J., Costa, F.M., and Turbin, M.S. Protective factors in adolescent problem behavior: Moderator effects and developmental change. Devel. Psychol. 31: 923-933, 1995.

JoHnson, D.R. Altemative methods for the quantitative analysis of panel data in family research: Pooled time-series models. J. Marr. Fam. 57: 1065-1077, 1995.

Johinston, L.D., O'Malley, P.M., Bachiman, J.G., AND Schulenberg, J.E. Monitoring the Future: National Survey Results on Drug Use, 19752003, Vol. 2, NIH Publication No. 04-5508, Bethesda, MD: Department of Health and Human Services, 2004.

KeELING, R.P. Drinking in college: The politics of research and prevention. J. Amer. Coll. Hlth 47: 51-55, 1998.

KIM, E.L., LARIMER, M.E., Walker, D.D., and MarlatT, G.A. Relationship of alcohol use to other health behaviors among college students. Psychol. Addict. Behav, 11: 166-173, 1997.

McClelland, G.H. AND Judd, C.M. Statistical difficulties of detecting interactions and moderator effects. Psychol. Bull. 114: 376-390, 1993.

MAGGS, J.L. Alcohol use and binge drinking as goal-directed action during the transition to postsecondary education. In: SchuleNBERG, J., MaGgs, J.L., AND HurRelmann, K. (Eds.) Health Risks and Developmental Transitions During Adolescence, New York: Cambridge Univ. Press, 1997, pp. 345-371.

Meimman, P.W. Alcohol-induced sexual behavior on campus. J. Amer. Coll. Hlth 42: 27-31, 1993.

Meiluan, P.W., Presley, C.A., AND CASHin, J.R. Average weekly alcohol consumption: Drinking percentiles for American college students. J. Amer. Coll. Hlth 45: 201-204, 1997.

O'MALLEY, P.M. AND Johinston, L.D. Epidemiology of alcohol and other drug use among American college students. J. Stud. Alcohol, Supplement No. 14, pp. 23-39, 2002.

Osgood, D.W., Johnston, L.D., O'Malley, P.M., and Bachiman, J.G. The generality of deviance in late adolescence and early adulthood. Amer. Sociol. Rev. 53: 81-93, 1988.

Perkins, H.W. Surveying the damage: A review of research on consequences of alcohol misuse in college populations. J. Stud. Alcohol, Supplement No. 14, pp. 91-100, 2002.

PERKINS, H.W. The emergence and evolution of the social norms approach to substance abuse prevention. In: PERKuns, H.W. (Ed.) The Social Norms Approach to Preventing School and College Age Substance
Abuse: A Handbook for Educators, Counselors, and Clinicians, San Francisco, CA: Jossey-Bass, 2003, pp. 3-17.

PERKINS, H.W. AND WeCHSLER, H. Variation in perceived college drinking norms and its impact on alcohol abuse: A nationwide study. J. Drug Issues 26: 961-974, 1996.

Rabe-Hesketh, S. AND Everrt, B. A Handbook of Statistical Analyses Using Stata, 3rd Edition, New York: Chapman and Hall, 2004.

READ, J.P., WOOD, M.D., AND CAPONE, C. A prospective investigation of relations between social influences and alcohol involvement during the transition into college. J. Stud. Alcohol 66: 23-34, 2005.

Read, J.P., WoOd, M.D., Kahler, C.W., Maddock, J.E., and Palfal, T.P. Examining the role of drinking motives in college student alcohol use and problems. Psychol. Addict. Behav. 71: 13-23, 2003.

Schulenderg, J.E. AND Maggs, J.L. A developmental perspective on alcohol use and heavy drinking during adolescence and the transition to young adulthood. J. Stud. Alcohol, Supplement No. 14, pp. 54-70, 2002.

Sher, K.J., Wood, M.D., Wood, P.K., AND RASKIN, G. Alcohol outcome expectancies and alcohol use: $A$ latent-variable cross-lagged panel study. J. Abnorm. Psychol. 105: 561-574, 1996.

StataCorp. Stata Cross-Sectional Time-Series: Reference Manual, Release 8.0, College Station, TX: Stata Corporation, 2003.

Wechsler, H., Dowdall, G.W., Davenport, A., and Castillo, S. Cortelates of college student binge drinking. Amer. J. Publ. Hlth 85: 921926, 1995.

Wechisler, H., Dowdall, G.W., Maenner, G., Gledhlll-Hort, J., and Lee, H. Changes in binge drinking and related problems among American college students between 1993 and 1997. J. Amer. Coll. Hith 47: 57$68,1998 \mathrm{a}$.

Wechsler, H., Isaac, N.E., Grodstein, F., and Sellers, D.E. Continuation and initiation of alcohol use from the first to the second year of college. J. Stud. Alcohol 55: 41-45, 1994.

WeChSLER, H., LEE, J.E., Kuo, M., AND LEE, H. College binge drinking in the 1990s: A continuing problem. Results of the Harvard School of Public Health 1999 College Alcohol Study. J. Amer. Coll. Hlth 48: 199-210, 2000.

WeChSLer, H., Lee, J.E., Kuo, M., Selbring, M., Nelson, T.F., and Lee, $\mathrm{H}$. Trends in college binge drinking during a period of increased prevention efforts. Findings from 4 Harvard School of Public Health College Alcohol Study surveys: 1993-2001. J. Amer. Coll. Hlth 50: 203-217, 2002.

WECISLER, H., RIGOTtI, N.A., GLEDHLL-HoYT, J., AND LEE, H. Increased levels of cigarette use among college students: A cause for national concern. JAMA 280: 1673-1678, $1998 \mathrm{~b}$.

Weitzana, E.R., NeLSON, T.F., AND WeChSLER, H. Taking up binge drinking in college: The influences of person, social group, and environment. J. Adolesc. Hith 32: 26-35, 2003.

Wood, M.D., Read, J.P., Palfal, T.P., and Stevenson, J.F. Social influence processes and college student drinking: The mediational role of alcohol outcome expectancies. J. Stud. Alcohol 62: 32-43, 2001.

Yu, J. AND Shacket, R.W. Alcohol use in high school: Predicting students' alcohol use and alcohol problems in four-year colleges. Amer. J. Drug Alcohol Abuse 27: 775-793, 2001. 


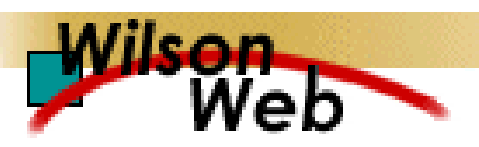

\section{COPYRIGHT INFORMATION}

TITLE: A Developmental Study of Heavy Episodic Drinking Among College Students

SOURCE: Journal of Studies on Alcohol 67 no1 Ja 2006

PAGE(S): 86-94

WN: 0600102128016

The magazine publisher is the copyright holder of this article and it is reproduced with permission. Further reproduction of this article in violation of the copyright is prohibited.

Copyright 1982-2006 The H.W. Wilson Company. All rights reserved. 